Research, part of a Special Feature on Scenarios of global ecosystem services

\title{
Trade-offs across Space, Time, and Ecosystem Services
}

\author{
Jon Paul Rodríguez ${ }^{1}, \underline{\text { T. Douglas Beard, Jr. }}{ }^{2}$, Elena M. Bennett ${ }^{3}$, Graeme S. Cumming ${ }^{4}$, Steven J. Cork ${ }^{5}$, \\ $\underline{\text { John Agard }}^{6}$, Andrew P. Dobson ${ }^{7}$, and Garry D. Peterson ${ }^{3}$
}

\begin{abstract}
Ecosystem service (ES) trade-offs arise from management choices made by humans, which can change the type, magnitude, and relative mix of services provided by ecosystems. Trade-offs occur when the provision of one ES is reduced as a consequence of increased use of another ES. In some cases, a trade-off may be an explicit choice; but in others, trade-offs arise without premeditation or even awareness that they are taking place. Trade-offs in ES can be classified along three axes: spatial scale, temporal scale, and reversibility. Spatial scale refers to whether the effects of the trade-off are felt locally or at a distant location. Temporal scale refers to whether the effects take place relatively rapidly or slowly. Reversibility expresses the likelihood that the perturbed ES may return to its original state if the perturbation ceases. Across all four Millennium Ecosystem Assessment scenarios and selected case study examples, trade-off decisions show a preference for provisioning, regulating, or cultural services (in that order). Supporting services are more likely to be "taken for granted." Cultural ES are almost entirely unquantified in scenario modeling; therefore, the calculated model results do not fully capture losses of these services that occur in the scenarios. The quantitative scenario models primarily capture the services that are perceived by society as more important - provisioning and regulating ecosystem services - and thus do not fully capture tradeoffs of cultural and supporting services. Successful management policies will be those that incorporate lessons learned from prior decisions into future management actions. Managers should complement their actions with monitoring programs that, in addition to monitoring the short-term provisions of services, also monitor the long-term evolution of slowly changing variables. Policies can then be developed to take into account ES trade-offs at multiple spatial and temporal scales. Successful strategies will recognize the inherent complexities of ecosystem management and will work to develop policies that minimize the effects of ES trade-offs.
\end{abstract}

Key Words: Ecosystem services; Millennium Ecosystem Assessment; space; time; synergisms; trade-offs

\section{INTRODUCTION}

Human societies have always relied on ecosystem services (ES) to enhance their well-being. Food, fiber, clean water, pollination, fertile soils, and recreation are just a few of the many services provided by nature to humans (Fig. 1, Ehrlich and Ehrlich 1992, Daily et al. 1997). Over time, we have also modified the supply of numerous ES to enhance the delivery or production of a particular good or service. For example, agriculture, forestry, and dam building are used by people to increase the availability of vegetables, wood, and water, respectively.
The principal challenges in managing ES are that they are not independent of each other (Heal et al. 2001, Pereira et al. 2005), and that the relationships between them may be highly non-linear (e.g., Farber et al. 2002, van Jaarsveld et al. 2005). Individual ES can be thought of as different elements of an interrelated whole or "bundle" (Cumming and Peterson 2005). Attempts to optimize a single service often lead to reductions or losses of other services-in other words, they are "traded-off" (Holling and Meffe 1996). For example, forested areas provide a variety of extractive and nonextractive goods and services (Rose and Chapman 2003). If a region is managed for mining, this may decrease its value for carbon sequestration, flood

\footnotetext{
${ }^{1}$ Instituto Venezolano de Investigaciones Cientificas, ${ }^{2}$ U.S. Geological Survey, ${ }^{3}$ McGill University, ${ }^{4}$ University of Florida, ${ }^{5}$ Land \& Water Australia, ${ }^{6}$ University of the West Indies, ${ }^{7}$ Princeton University
} 
control, or wilderness and biodiversity protection. Knowledge and awareness of the interactions between ES are necessary for making sound decisions about how to manage natural systems appropriately (e.g., Grasso 1998, Kearns et al. 1998, Higgins et al. 1999, Balvanera et al. 2001, Rose and Chapman 2003).

In this article, we focus on societal ES management decisions that may negatively affect the provision of other ES. After defining and characterizing ES trade-offs, we explore some examples of the most frequent ES trade-offs faced by society. We elaborate on future trade-offs in the context of the Millennium Ecosystem Assessment (MA) scenarios (Carpenter et al. 2006, Cork et al. 2006), and conclude by summarizing the principal lessons learned. A broader treatment of the topic of interactions among ES (which also includes synergies) may be found in Rodríguez et al. (2005), and an analysis of trade-offs in the MA sub-global assessments, as well as methods for guiding decision makers, are developed by Pereira et al. (2005).

Although trade-offs are becoming a popular topic of inquiry in ecology, few studies have brought together examples from across disciplines and around the planet, as we do here. Additionally, the nature of scenarios insists that we focus on the impact that current decisions may have on the future, which is a unique aspect of this review paper. Tradeoffs have an impact on current provision of ES, but our analysis shows that their impact on future provision of services, which often has unknown or unanticipated aspects, can be even greater. By highlighting the impacts of trade-offs on the future supply of ES, we focus on a critical part of making better decisions about trade-offs themselves.

\section{WHAT IS AN ECOSYSTEM SERVICE TRADE-OFF?}

Ecosystem service trade-offs arise from management choices made by humans, which can change the type, magnitude, and relative mix of services provided by ecosystems. Trade-offs occur when the provision of one ES is reduced as a consequence of increased use of another ES. In some cases, a tradeoff may be an explicit choice; but in others, tradeoffs arise without premeditation or even awareness that they are taking place. These unintentional trade- offs happen when we are ignorant of the interactions among ES (e.g., Tilman et al. 2002, Ricketts et al. 2004), when our knowledge of how they work is incorrect or incomplete (Walker et al. 2002), or when the ES involved have no explicit markets. But even when a decision is the result of an explicit, informed choice, the decision may have negative implications. For example, adverse impacts may arise as a consequence of the scale mismatch between the intent of a particular management decision, the expected outcome, and the long-term or broad spatial scale of the decisions (van Jaarsveld et al. 2005). Ecosystem feedbacks and food web dynamics can also lead to unexpected consequences (Ostfeld and LoGiudice 2003). As either the temporal or spatial scale increases, trade-offs become more uncertain and difficult to manageeven with adequate knowledge. As human societies continue to transform ecosystems to obtain greater provision of specific services, we will undoubtedly diminish some to increase others (Foley et al. 2005).

Ecosystem services trade-offs can be classified along three axes: spatial scale, temporal scale, and reversibility (Fig. 2). "Spatial scale" refers to whether the effects of the trade-off are felt locally or at a distant location. "Temporal scale" refers to whether the effects take place relatively rapidly or slowly. "Reversibility" expresses the likelihood that the perturbed ES may return to its original state if the perturbation ceases.

Because many management actions affect more than one ES at a time, and may operate at different scales simultaneously, it can be difficult to classify ES interactions in a single category. At the same time, however, knowledge of the different scales at which policies should be targeted is a key component of managing ES.

\section{ES Trade-offs in Space}

Environmental economists use "externality" to refer to the effects of an ES management decision that are borne by others than those benefiting from the targeted ES (Tietenberg 1996). For example, the diversion of water from a river to provide drinking water for a town, or irrigation water to an agricultural area, will leave people downstream without water to meet their own needs. The use of water upstream imposes an externality on those living lower down the watershed.

Spatial trade-offs are among those most commonly 
Fig. 1. Ecosystem services are the benefits that people obtain from ecosystems. They include provisioning, regulating, and cultural services that directly affect people, and supporting services needed to maintain the other services. Biodiversity underlies all ecosystem services (source: Millennium Ecosystem Assessment Synthesis Report, http://www.maweb.org//en/Products.Synthesis.aspx).

\section{ECOSYSTEM SERVICES}

\section{Supporting}

NUTRIENT CYCLING

- SOIL FORMATION

- PRIMARY PRODUCTION

I...

\section{Provisioning}

FOOD

FRESH WATER

WOOD AND FIBER

FUEL

\section{Regulating}

- CLIMATE REGULATION FLOOD REGULATION DISEASE REGULATION WATER PURIFICATION ...

\section{Cultural}

AESTHETIC

SPIRITUAL

- EDUCATIONAL

RECREATIONAL 
Fig. 2. Eight categories of ecosystem service trade-offs, classified according to their spatial and temporal scales, and their degree of reversibility (Excerpted from Millennium Ecosystem Assessment. 2005. Ecosystems and Human Well-Being: Scenarios, Volume 2. Copyright (C) 2005 by the author. Reproduced by permission of Island Press, Washington, D.C.).

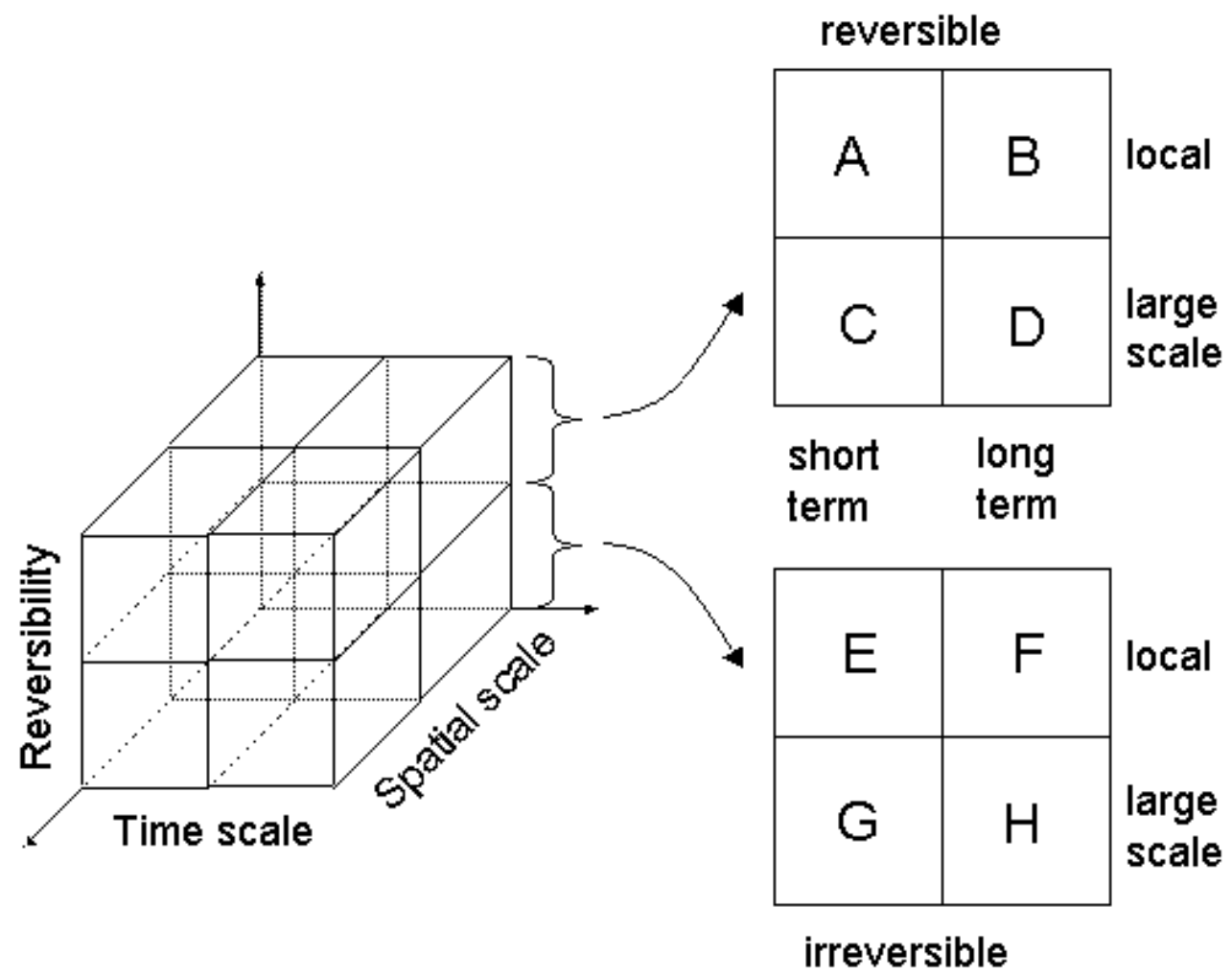

observed in human societies (Rodríguez et al. 2005). They are frequently linked to the use of a provisioning service, which is traded-off against another ES, e.g., when decisions about increasing agricultural production by increasing fertilizer use have broad-scale effects on water quality. This is illustrated by agricultural production in the USA, which is a compelling example of a spatial ES tradeoff (Tilman 1999, Tilman et al. 2002).

Highly productive, intensive agriculture within the
USA relies on the addition of either natural (manure) or chemical fertilizers. The effects of the high level of artificial fertilization have resulted in massive changes in downstream areas. The cumulative effect of small-scale fertilization by many individual farmers has been the creation of a hypoxic ("dead") zone in the Gulf of Mexico (Cumming and Peterson 2005). The dead zone has resulted in declines in the shrimp fishery, as well as in other local fisheries in the Gulf region (Malakoff 1998). Attempts to maintain and increase the provision of one service, 
Fig. 3. Generalized schematic sequence of land-cover changes from before human settlement to the human domination of the landscape (adapted from DeFries et al. 2004).

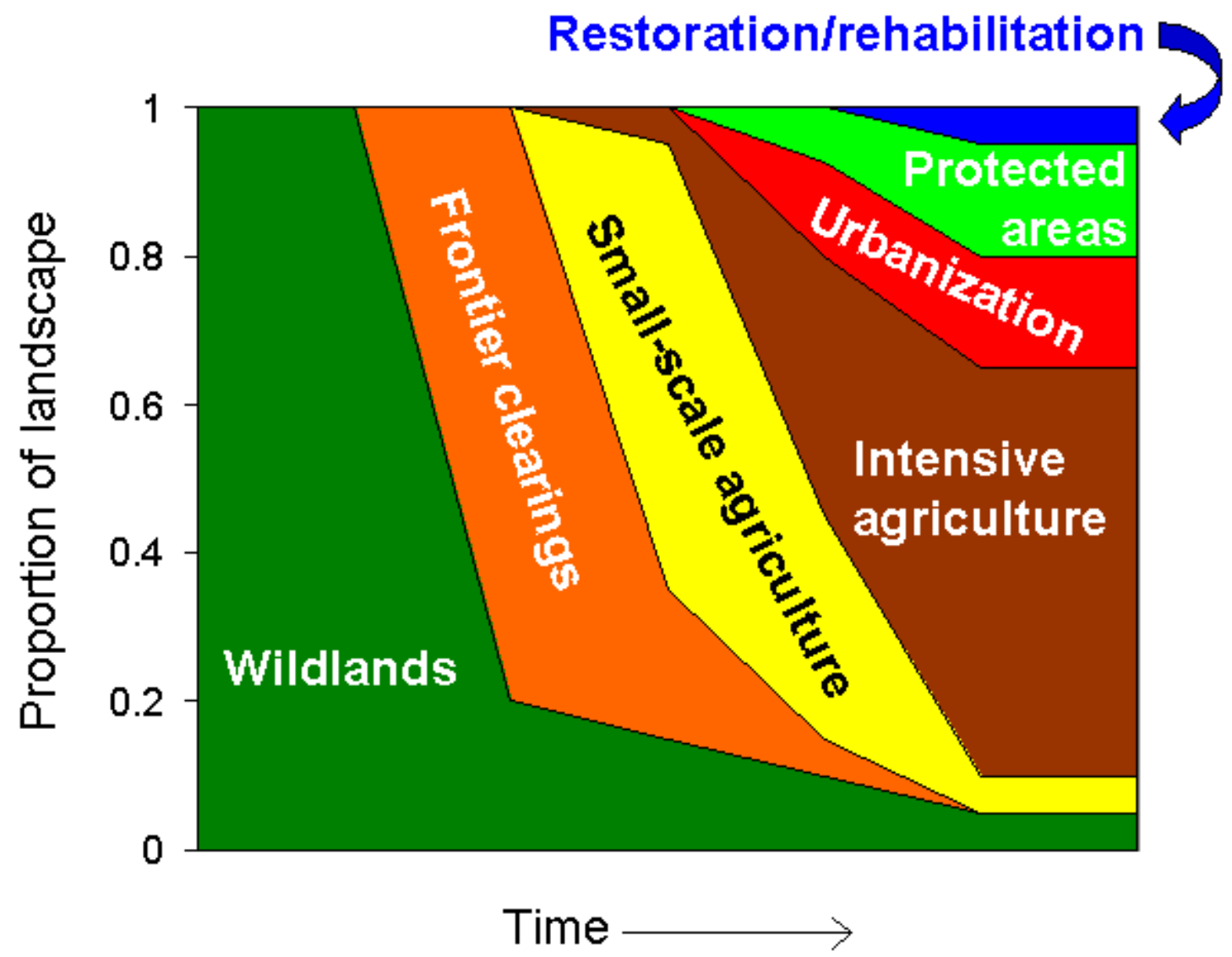

food, have caused substantial declines in many ES in another location (Tilman et al. 2002). The effects of this trade-off are felt over a large spatial scale, and are likely to last for a long time. Indeed, some of them may be irreversible.

Analogous cases from other parts of the world also exist (Pereira et al. 2005, van Jaarsveld et al. 2005). For example, bluegum (Eucalyptus globulus) plantations in the Nilgiri Plateau in southern India provide industry with paper pulp and tannin, but have reduced water yield from catchments by up to $23 \%$, thereby affecting downstream hydropower projects (Samraj et al. 1988).

\section{ES Trade-offs in Time}

Management decisions often focus on the immediate provision of an ES, at the expense of this same ES or other services in the future. Such decisions are prevalent in democratic societies, where the term of elected officials is short enough that the ecological impacts of their decisions will probably be confronted by others than themselves (i.e., the consequences of poor decisions become 
externalities that are borne by future politicians). Temporal externalities are not just a political problem, however; many natural processes, such as those that create soil or alter soil fertility and groundwater levels, occur at such slow rates that several generations may pass before significant effects are perceived by humans. In each case, the principal characteristic of an ES trade-off in time is that the short-term needs of society drive decisions about ES management, purposely or inadvertently ignoring the future consequences of these actions.

Dryland salinization has been a major issue facing farmers in Australia since the 1930s. It was not until the late 1980s and early 1990s, however, that the problem moved from being individual to collective (Anderies et al. 2001, Greiner and Cacho 2001, Briggs and Taws 2003). To increase agricultural production (a provisioning service), many farmers cleared the original woody vegetation and replaced it with pastures and crops (Schofield 1992, Farrington and Salama 1996). The naturally forested landscape of Australia had provided an important but undervalued regulating service by maintaining the groundwater at low enough levels that salts were not carried upward through the soil. Once the woody vegetation was removed, the water table moved toward the surface, bringing salt from the basement complex into the surface soils. As the salt content in soils increases, lands become unusable for traditional agriculture (Anderies et al. 2001, Greiner and Cacho 2001, Briggs and Taws 2003). A short-term focus on agricultural production led to the longer-term loss of soil quality. Current ecological restoration efforts include planting trees in plots contiguous to fields to recover the ES provided by native vegetation (Schofield 1992, Farrington and Salama 1996).

\section{Reversibility of ES}

An example of the degrees of reversibility of ES is provided by lakeshore development in the northern USA. Property values surrounding lakes in northern Wisconsin in the USA are linked to the development patterns around the lake. During the last 30 years, there has been a substantial increase in the development and building on lake shores (Peterson et al. 2003) that has resulted in the creation of a "lake community" on many lakes. The initial conversion of these lakes from undeveloped to developed shorelines resulted in an increase in property values around these waters. Although development was accompanied by an initial increase in cultural ES, changes in shoreline vegetation resulted in increased sedimentation (soil loss; soil provides a supporting ES), a reduction of the amount of habitat (a regulating ES) available for fishes (Christensen et al. 1996), and a decrease in fish growth rates (Schindler et al. 2000). In turn, fish growth is directly related to fish production, which is a provisioning ES.

Although zoning regulations can help to control shoreline development, lake communities are often resistant to zoning and control, even though there is evidence that zoning results in even higher increases in property value (Spaltro and Provencher 2001). In addition, shoreline developments often lead to increases in primary production due to increased fertilizer use and sedimentation from runoff. The consequence is a decrease in water quality (regulating ES) and subsequent reduction in the aesthetic quality of the lake (cultural ES).

Resistance to zoning and government regulation by property owners in this area led to overdevelopment and the environmental impacts just discussed. It remains to be seen whether the long-term cumulative environmental impact will adversely affect property values. Several types of trade-offs are involved here. For example, the reduction of fish habitat is probably irreversible, local, and rapid (Type E, Fig. 2), whereas decreases in water quality and aesthetic value of lakes may be reversible (with successful enforcement of regulations on fertilizer use), large scale, and long term (Type D, Fig. 2).

\section{Trade-offs across ES}

Trade-offs do not only occur across space and time, and have different degrees of reversibility, but usually result in more than one ES traded-off for the ES being enhanced. For example, the management of a forest for tree production (a provisioning service) may also affect water quality downstream (a regulating service) or decrease the value of the land for recreation (a cultural service) (e.g., Rose and Chapman 2003, Maass et al. 2005, van Jaarsveld et al. 2005).

The recent sudden decline of Gyps vultures in eastern India provides a compelling example of how the decline of a single species can cause declines in provision of many ES, illuminating unexpected interactions between species and socioecological 
Fig. 4. Relative change in provision of ecosystem services (ES) in the four scenarios. Red polygons ("stars") indicate the state of each ES at the end of the scenario storyline relative to a starting point of zero (indicated by green stars). A positive value (between 0 and 1) indicates an increase in the supply of a particular ES. A negative value (between 0 and -1) indicates a decrease in supply. Therefore, as the red stars are bigger, the overall supply of ES increases, but as they decrease, the overall supply of ES decreases (Excerpted from Millennium Ecosystem Assessment. 2005. Ecosystems and Human Well-Being: Scenarios, Volume 2. Copyright (C 2005 by the author. Reproduced by permission of Island Press, Washington, D.C.).
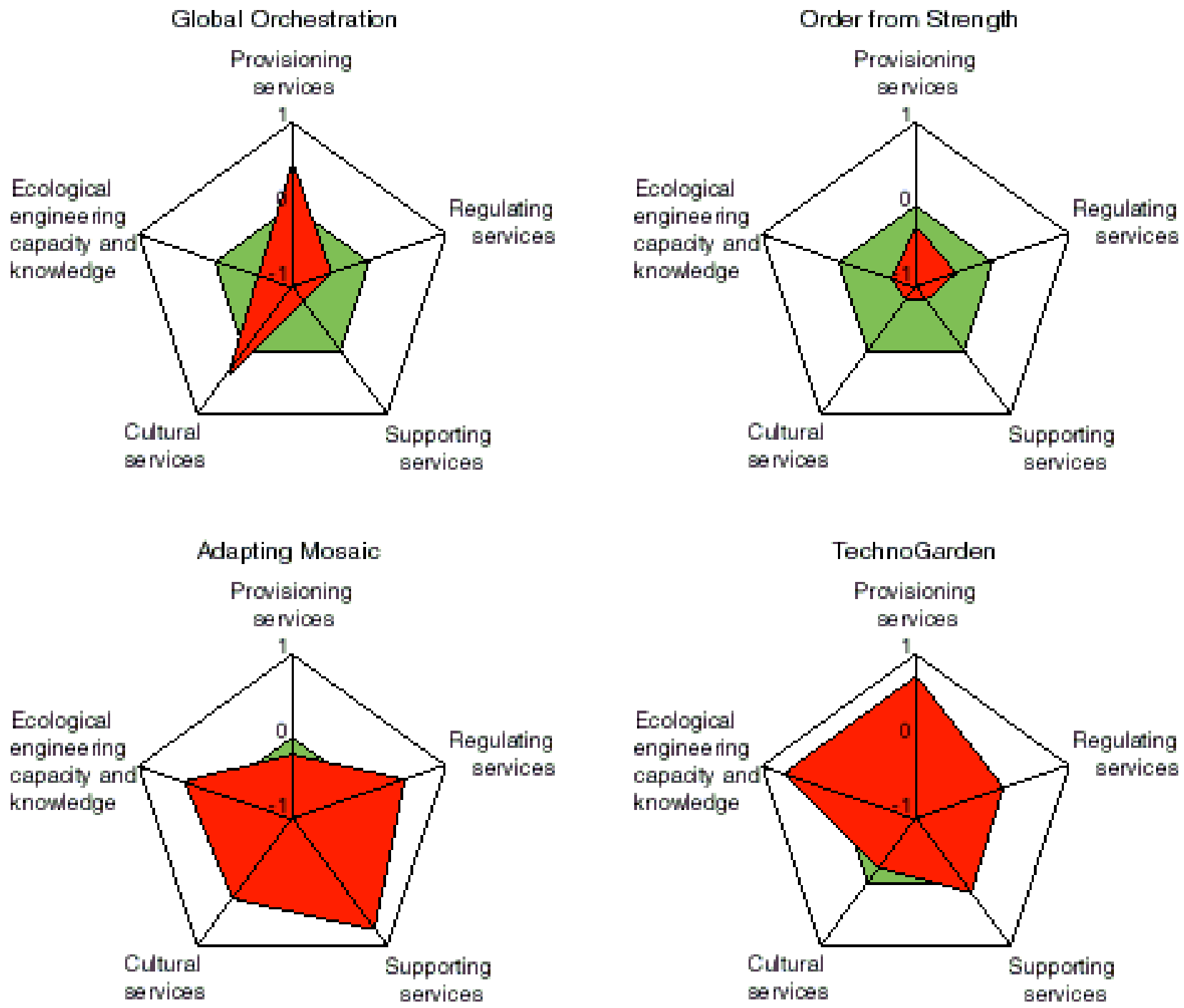

processes. Vultures play an important role as natural garbage collectors in many parts of India. In particular, vultures help dispose of cattle carcasses in areas where beef eating is forbidden (Pain et al. 2003, Green et al. 2004). In Amritsar, center of the Parsi religion, they also help remove human corpses from traditional sites of "laying to rest."
In recent years, vulture numbers have suddenly declined, with consequences that have cascaded throughout the region. As there are too few vultures to clean the corpses, the Parsi are no longer able to lay their dead to rest without causing a health hazard (Ramesh 2005). Instead, the dead are stored until a future time. But the less obvious consequences of the decline in the vulture population are leading to 
even more dramatic effects. Carcasses of cattle are disposed of in areas on the edges of towns and villages. These areas are now becoming increasingly dangerous to visit because vultures do not rapidly remove the meat from carcasses, tempting other carnivores to the area. Feral dog populations have increased as a result of the lower competition with vultures for meat. Growing dog populations are likely to cause an increase in rabies risk, dramatically heightening the consequences of being attacked by a dog (Youth 2002).

Vulture declines have recently been linked to the use of the cattle anti-inflammatory drug diclofenac (Green et al. 2004, Oaks et al. 2004). Thus, in this example, attempts to improve the health of domestic animals had a series of cascading, unanticipated, and unknown effects on many other services, including a likely impact on human health in the area.

\section{MOST COMMON TYPES OF ECOSYSTEM SERVICE TRADE-OFFS}

In general terms, the preferences of human societies for the services provided by ecosystems seem to focus first on provisioning services, followed by regulating, cultural, and supporting services, in that order (Foley et al. 2005, Pereira et al. 2005, Rodríguez et al. 2005, van Jaarsveld et al. 2005). This hierarchy of preference parallels the sequence of events that take place after human colonization of a new unsettled area, which is also linked to the short-term needs of humans (Fig. 3, DeFries et al. 2004).

Initially, as the human frontier reaches wildlands, land is rapidly cleared to establish small-scale agricultural developments that sustain a small, but growing population. At this stage, the main interest is provisioning services: driven by agricultural production, other ES are traded-off against the provision of food, fiber, fuel, etc. In areas where the soil is sufficiently fertile for degradation not to occur immediately, "subsistence" lifestyles are then replaced by industrial agricultural operations and urban developments, while wildlands conversion continues, albeit at a lower rate. Regulating services now increase in importance because, as the impact on humans on the landscape grows, processes such as water regulation and purification must be enhanced. In the final stages, a portion of the landscape is set aside as protected or recreational areas, and another is managed as restored or rehabilitated ecosystems. It is not until late in the process that societies, faced with an ever shrinking wilderness, focus on conservation and restoration. For example, after the destruction of about $60 \%$ of wetlands in the midwestern USA for farming purposes, restoration is now considered a priority and has received governmental support through the 2002 Farm Bill (Zedler 2003).

Decisions about ES typically default to the shortterm needs of humans, even when such decisions might interfere with ES that are necessary for the long-term sustainability of human well-being (Foley et al. 2005). The heavy emphasis on provisioning ES could be the consequence of their value being more tangible and identifiable by societies, whereas the economic value of cultural, regulating, and supporting services are more difficult to quantify.

At some point, however, cultural services may become critical and trade-offs may occur between different cultural services. For example, people recognize "their" country by its typical plants, animals, and landscape features. Although for some the cultural value of landscapes increases as they approach a "wilderness" condition, others, e.g., farmers in countries as diverse as Australia and Switzerland, feel uncomfortable if tree cover is increased beyond a threshold (Hunziker 1995, Cary and Williams 2000).

Managers of freshwater systems also face a typical and difficult set of possible trade-offs (e.g., Samraj et al. 1988, Jackson et al. 2001, Lenton 2004, Chermak et al. 2005, Stamenkovic et al. 2005). Water is removed from streams and lakes for drinking, sanitation, irrigation, and industry. These uses frequently conflict with other freshwater services that rely on the maintenance of stream flow or lake levels, such as power generation, fish production, transport, waste removal, and recreation. Conflicts over surface water are often resolved by use of groundwater, which may influence surface water directly by reducing the height of the water table and causing formerly perennial rivers to become seasonal. Many towns in the USA currently use fossil water that is extracted from aquifers at a rate that is too rapid to allow for replenishment, an approach that simply defers the problem until a future time when it is 
blindly hoped that the demand for freshwater will be lower.

\section{ECOSYSTEM SERVICE TRADE-OFFS IN THE MILLENNIUM ECOSYSTEM ASSESSMENT SCENARIOS}

One of the tasks of the Scenarios Working Group of the MA was to evaluate a set of plausible futures for ES on Earth: Global Orchestration, Order from Strength, Adapting Mosaic, and TechnoGarden (Carpenter et al. 2006, Cork et al. 2006). In all scenarios, society modifies the supply of a variety of ES (Fig. 4). Broadly speaking, under the two "reactive" scenarios (Global Orchestration and Order from Strength), the losses are greater than the gains. Even in the "proactive" scenarios (Adapting Mosaic and TechnoGarden), however, there are slight relative reductions in the supply of ES in one of the dimensions considered.

In Global Orchestration, society focuses primarily on the provisioning ES that generate tangible products to improve human well-being. When environmental problems arise, they are dealt with according to the belief that economic growth can always provide resources to substitute for lost ecosystem functions. Under this scenario, society's confidence in its ability to develop technological replacements or enhancements for regulating and supporting ES, leads to these services being tradedoff while provisioning ES are maximized. In many cases, this confidence is misplaced either because the replacements are not possible or because they take so long and cost so much to develop that society loses both economically and in terms of net wellbeing.

Because of the focus on global public goods and services like education, health, and cultural fulfillment, in this scenario, cultural ES are treated differently from other ES. Regulating and supporting services are routinely ignored in tradeoff decisions, because in many instances in this scenario, the potential decline in human well-being is deferred until cumulative loss of biodiversity passes some critical threshold. For example, increased human and economic well-being leads to urban growth into wetlands and along coastlines, which in the short term, provides wealth, food, and comfort for humans, but ultimately causes the diminishment of nutrient cycling and water purification and the elimination of fish habitat within these areas. People in this scenario typically ignore these negative effects until they are a serious problem. In contrast, there is some recognition that cultural ES or cultural differences are essential to maintain.

At the same time, the emphasis on free trade and global policy within the Global Orchestration scenario, causes many cultures to be subsumed into an overall "global culture." For example, even though some aspects of Asian culture may be integrated into western business practices, many of the traditional practices, such as religious ceremonies, are eliminated as these cultures strive to become part of the global community. This process causes culturally important aspects of ecosystems to be overlooked as well.

The increased importance of meat in the diet in this scenario is an example of an interaction between global culture and provisioning ES. This results from a general increase in prosperity of previously poor countries and a desire to achieve the lifestyle of other wealthy cultures. The increased production of meat causes extensification of agriculture to provide animal feed. This extensification happens at the cost of land-based biodiversity. This and other similar trade-offs are largely ignored in this scenario, as this change in diet is viewed as a benefit of Global Orchestration policies.

Order from Strength places little value on ES, because rich and poor countries are both focused on increasing their wealth and power through economic growth and defense of their borders. All ES, but especially those that occur over large spatial or temporal scales, are likely to be traded-off, as there are no international mechanisms or incentives to protect them. In rich countries, ecosystems are believed to be robust and, therefore, are used without restrictions in order to improve human wellbeing. All that is required is that representative samples are preserved in order to have a "natural database" for developing appropriate technologies to repair or replace them. Provisioning ES are likely to be favored without considering the impacts on other ES, as they directly improve human wellbeing. Uses of ES that have negative impacts spatially (e.g., harvesting that causes erosion, decline in water or air quality, or loss of amenity) are externalized by rich countries by encouraging poorer countries to perform these activities out of economic necessity. In poor countries, the conservation of ES is not considered a priority, 
because alleviation of poverty by the fastest means possible is essential. Thus substantial trade-offs occur among all services. Little thought can be given to how environmental problems incurred through trade-off decisions will be repairable at a later date.

The lack of value placed on ES in Order from Strength can perhaps best be illustrated by the examples drawn from marine fisheries and the plight of sub-Saharan Africa (Cumming and Peterson 2005). In marine fisheries management in Order from Strength, the rich countries use their wealth to control global fisheries while protecting their own stocks. Their emphasis is not on maintaining adequate provisioning resources for human well-being. Instead, they focus on controlling the global market for fisheries to maximize economic gain. Exports of small pelagic fishes are diverted for further production of meat (a luxury food resource in rich countries) instead of being exported as food products to poor countries. In contrast to the rich countries, most of sub-Saharan Africa no longer has food security in 2050 , because of the effects of climate modification and population growth in this region. The decision for policy makers is not about trading off provisioning services for other ES, but instead is solely focused on maintaining their own food security.

Under Adapting Mosaic, there is no dominant ES trade-off paradigm, although trade-offs tend to decline over time. In the short term, societies are likely to engage in a variety of ES trade-offs as they experiment with the supply of ES according to their local needs, especially provisioning services. No single trade-off dominates, because conditions vary globally and societies only focus on their local set of conditions and problems. Over time, local management improves throughout the world. Local institutions and innovations reduce the number and magnitude of trade-offs.

Unintended spatial trade-offs are a risk in Adapting Mosaic, as the focus on local management of ecosystems leads initially to competition between regions and lack of effective strategic management at large scales. This scenario would eventually have led to breakdown of ES operating over large spatial scales (e.g., maintenance of hydrological cycles, including groundwater and river flows, maintenance of atmospheric composition, and regulation of migratory pests and diseases) had not people organized regionally, nationally, and globally from the bottom up.
The Adapting Mosaic scenario leads to many local management examples that build on previous experiences and deal with each set of trade-offs independently. For example, in the EuphratesTigris river (Cumming and Peterson 2005), the initial trade-off decisions provide more provisioning services (cotton production) at the expense of supporting and regulating services (soil formation, saline control on the land). However, working within the area, managers learn how to use the Adapting Mosaic of conserved areas to eventually craft solutions that provide for "win-win" interactions in provisioning, regulating, and supporting ES. Similarly, malaria control in Africa (Cumming and Peterson 2005) involves the tradeoff of a regulating ES (disease control) with a provisioning service (fresh water), as water is drained to reduce mosquito breeding areas. Through the use of adaptive management on a fairly small scale, however, managers are able to craft solutions that produce "win-win" solutions that provide both fresh water and malaria control.

TechnoGarden assigns high values to ES, but mainly from a pragmatic perspective. This means that cultural ES are more likely to be traded-off and lost than other types of services, especially as land management in some areas becomes dominated by large corporations and people move toward urban centers. Initially, there is great interest in the variety of provisioning, regulating, and supporting ES as models for possible technological developments, but as key societal ES are identified and replaced by technological equivalents, society becomes more likely to trade-off any existing ES for their engineered alternatives. In the short term, society will predominantly trade-off cultural ES for other types of services; in the long term, all types of services may be traded-off as key ES are identified and technologically optimized.

The emphasis on technological fixes leads to the rapid urbanization of many parts of the globe, especially in Asia. As urban areas grow, traditional cultural resources such as temples and religious sanctuaries are traded-off for urban areas. This is not a long-term solution, however, as there still is a need for cultural services, and many are "reinvented:" the rebirth of Japanese urban gardens, for instance, or the creation of salmon festivals in the U.S. Pacific Northwest, and the Gojiro festivals in Japan.

One of the most important conclusions from all 
scenarios is that the total pressure on ES worldwide will increase. Some of this is a consequence of the projected human population growth used in these scenarios. Even in cases such as TechnoGarden and Adapting Mosaic (which attempt to mitigate some of these environmental pressures), increases in provisioning ES will be traded-off against supporting and regulating services. There is perhaps no more compelling example than the combined synergistic effect of greater use of greenhouse gases (through increased human population and a greater reliance on fossil fuel technology) and the decline in carbon sequestration that has resulted from the conversion of forested areas into agriculture. Thus, the ability of the biosphere to regulate climate change-even with the technological fixes expected in TechnoGarden or the localized controls of Adapting Mosaic - will not be easily restored, as the regulating and supporting services provided by forests are traded-off by the additional expansion of agriculture, a provisioning service.

\section{CONCLUSIONS}

Ecosystem services trade-offs arise from management choices made by humans, who intentionally or otherwise change the type, magnitude, and relative mix of services provided by ecosystems. Trade-offs occur when the provision of one ES is reduced as a consequence of increased use of another ES. Trade-offs can be classified in terms of their temporal and spatial scales, and their degree of reversibility. Identifying trade-offs allows policy makers to understand the long-term effects of preferring one ES over another, and the consequences of focusing only on the present provision of a service rather than its future.

Important specific trade-offs are those between agricultural production and other ES, such as biodiversity, water and soil quality, and water availability for other present and future uses. Technological or institutional advances that mitigate such trade-offs will improve ES and simplify the factors that must be considered when making decisions, however, these trade-offs need to be understood and acknowledged at all steps of the decision-making process.

Across all four MA scenarios and case study examples, trade-off decisions show a preference for provisioning, regulating, or cultural services (in that order). Supporting services are more likely to be "taken for granted." Cultural ES are almost entirely unquantified in scenario modeling; therefore, the calculated model results do not fully capture losses of these services that occur in the scenarios. The quantitative scenario models primarily capture the services that are perceived by society as more important — provisioning and some regulating ESand thus do not fully capture trade-offs of cultural and supporting services.

However, each of the MA scenarios takes a different approach to trade-offs. In Global Orchestration, society gives preference to provisioning ES. In Order from Strength, present use of ES is favored over potential future uses. Under Adapting Mosaic, there is no dominant type of trade-off because most decisions are made locally. However, the approach to trade-offs becomes more ecologically sound, as previously unidentified trade-offs and synergisms are revealed through learning and incorporated into decision making. There is greater opportunity for institutional solutions to trade-off problems in Adapting Mosaic. In TechnoGarden, cultural services are undervalued and often traded-off in management decisions. There is greater opportunity for technological solutions to trade-off problems in TechnoGarden.

Effective decision making, which allows policy makers to include a comprehensive view of ES trade-offs, should address the cumulative and synergistic effects of their decisions. In addition, policies need to acknowledge that, in many instances, short-term demands on ES will affect the longer-term, larger-scale provision of these or other ES. Successful management policies will be those that incorporate lessons learned from prior decisions into future management actions. Managers should complement their actions with monitoring programs that, in addition to monitoring the short-term provision of services, also monitor the long-term evolution of slowly changing variables. Policies can then be developed to take into account ES trade-offs at multiple spatial and temporal scales. Successful strategies will recognize the inherent complexities of ecosystem management and will work to develop policies that minimize the effects of ES trade-offs. 
Responses to this article can be read online at:

http://www.ecologyandsociety.org/voll1/iss 1/art28/responses/

\section{Acknowledgments:}

We are grateful to the extensive feedback provided by Steve Carpenter, Bach Tan Sinh, Christopher Field, Monika Zurek, Julian Caley, Paul Ehrlich, Steve Freeman, Elizabeth Martin, R. E. Munn, Harini Nagendra, Karin Limburg, Louis Pitelka, Linda Starke, Tom Tomich, Matthew Wilson, two anonymous reviewers, and the many others who commented on previous versions of the "trade-offs working group" documents. Figures 2 and 4 were kindly prepared by Kathryn M. Rodríguez-Clark.

\section{LITERATURE CITED}

Anderies, J. M., G. Cumming, M. Janssen, L. Lebel, J. Norberg, G. Peterson, and B. Walker. 2001. A resilience centered approach for engaging stakeholders about regional sustainability: an example from the Goulburn Broken catchment in Southeastern Australia. Technical Report, CSIRO Sustainable Ecosystems.

Balvanera, P., G. C. Daily, P. R. Ehrlich, T. H. Ricketts, S. A. Bailey, S. Kark, C. Kremen, and H. Pereira. 2001. Conserving biodiversity and ecosystem services. Science 291:2047-2047.

Briggs, S. V., and N. Taws. 2003. Impacts of salinity on biodiversity-clear understanding or muddy confusion? Australian Journal of Botany 51:609617.

Carpenter, S. R., E. M. Bennett, and G. D. Peterson. 2006. Scenarios for ecosystem services: an overview. Ecology and Society 11(1): 29. [online] URL: http://www.ecologyandsociety.org/voll1/ iss1/art29/.

Cary, J., and K. Williams. 2000. The value of native vegetation: urban and rural perspectives. National Research and Development Program on Rehabilitation, Management and Conservation of Remnant Vegetation, Research Report RR 3/00. Land and Water Resources Research and
Development Corporation, Canberra, Australia.

Chermak, J. M., R. H. Patrick, and D. S. Brookshire. 2005. Economics of transboundary aquifer management. Ground Water 43:731-736.

Christensen, D. L., B. R. Herwig, D. E. Schindler, and S. R. Carpenter. 1996: Impact of lakeshore residential development on coarse woody debris in North temperate lakes. Ecological Applications 6:1143-1149.

Cork, S. J., G. D. Peterson, E. M. Bennett, G. Petschel-Held, and M. Zurek. 2006. Synthesis of the storylines. Ecology and Society, in press.

Cumming, G., and G. Peterson. 2005. Ecology in global scenarios. Pages 45-70 in S. R. Carpenter, P. L. Pingali, E. M. Bennett, and M. B. Zurek, editors. Ecosystems and human well-being: scenarios, Volume 2. Findings of the Scenarios Working Group, Millennium Ecosystem Assessment. Island Press, Washington, D.C., USA.

Daily, G. C., S. Alexander, P. R. Ehrlich, L. Goulder, J. Lubchenco, P. A. Matson, H. A. Mooney, S. Postel, S. H. Schneider, D. G. Tilman, and G. M. Woodwell. 1997. Ecosystem services: benefits supplied to human societies by natural ecosystems. Issues in Ecology 2:1-16.

DeFries, R. S., J. A. Foley and G. P. Asner. 2004. Land-use choices: balancing human needs and ecosystem function. Frontiers in Ecology and the Environment 2:249-257.

Ehrlich, P. R., and A. H. Ehrlich. 1992. The Value of Biodiversity. Ambio 21:219-226.

Farber, S. C., R. Costanza, and M. A. Wilson. 2002. Economic and ecological concepts for valuing ecosystem services. Ecological Economics 41:375-392.

Farrington, P., and R. B. Salama. 1996. Controlling dryland salinity by planting trees in the best hydrogeological setting. Land Degradation \& Development 7:183-204.

Foley, J. A., R. DeFries, G. P. Asner, C. Barford, G. Bonan, S. R. Carpenter, F. S. Chapin, M. T. Coe, G. C. Daily, H. K. Gibbs, J. H. Helkowski, T. Holloway, E. A. Howard, C. J. Kucharik, C. Monfreda, J. A. Patz, I. C. Prentice, N. 
Ramankutty, and P. K. Snyder. 2005. Global consequences of land use. Science 309:570-574.

Grasso, M. 1998. Ecological-economic model for optimal mangrove trade off between forestry and fishery production: comparing a dynamic optimization and a simulation model. Ecological Modelling 112:131-150.

Green, R. E., I. Newton, S. Shultz, A. A. Cunningham, M. Gilbert, D. J. Pain, and V. Prakash. 2004. Diclofenac poisoning as a cause of vulture population declines across the Indian subcontinent. Journal of Applied Ecology 41:793800 .

Greiner, R., and O. Cacho. 2001. On the efficient use of a catchment's land and water resources: dryland salinization in Australia. Ecological Economics 38:441-458.

Heal, G., G. C. Daily, P. R. Ehrlich, J. Salzman, C. Boggs, J. Hellman, J. Hughes, C. Kremen, and T. Ricketts. 2001. Protecting natural capital through ecosystem service districts. Stanford Environmental Law Journal 20:333-364.

Higgins, S. I., C. M. Shackleton, and E. R. Robinson. 1999. Changes in woody community structure and composition under contrasting landuse systems in a semi-arid savanna, South Africa. Journal of Biogeography 26:619-627.

Holling, C. S., and G. K. Meffe. 1996. Command and control and the pathology of natural resource management. Conservation Biology 10:328-337.

Hunziker, M. 1995. The spontaneous reafforestation in abandoned agricultural lands-perception and aesthetic assessment by locals and tourists. Landscape and Urban Planning 31: 399-410.

Jackson, R. B., S. R. Carpenter, C. N. Dahm, D. M. McKnight, R. J. Naiman, S. L. Postel, and S. W. Running. 2001. Water in a changing world. Ecological Applications 11:1027-1045.

Kearns, C. A., D. W. Inouye, and N. M. Waser. 1998. Endangered mutualisms: the conservation of plant-pollinator interactions. Annual Review of Ecology and Systematics 29:83-112.

Lenton, R. 2004. Water and climate variability: development impacts and coping strategies. Water
Science and Technology 49:17-24.

Maass, J., P. Balvanera, A. Castillo, G. Daily, H. Mooney, P. Ehrlich, M. Quesada, A. Miranda, V. Jaramillo, F. García-Oliva, A. Martínez-Y rizar, H. Cotler, J. López-Blanco, A. Pérez-Jiménez, A. Búrquez, C. Tinoco, G. Ceballos, L. Barraza, R. Ayala, and J. Sarukhán. 2005. Ecosystem services of tropical dry forests: insights from long-term ecological and social research on the Pacific Coast of Mexico. Ecology and Society 10(1):17. [online] URL: http://www.ecologyandsociety.org/vol10/iss 1/ art17/.

Malakoff, D. 1998. Death by suffocation in the Gulf of Mexico. Science 281:190-192.

Oaks, J. L., M. Gilbert, M. Z. Virani, R. T. Watson, C. U. Meteyer, B. Rideout, H. L. Shivaprasad, S. Ahmed, M. J. I. Chaudhry, M. Arshad, S. Mahmood, A. Ali, and A. A. Khan. 2004. Diclofenac residues as the cause of population decline of vultures in Pakistan. Nature 427:630 633.

Ostfeld, R. S., and K. LoGiudice. 2003. Community disassembly, biodiversity loss, and the erosion of an ecosystem service. Ecology 84:14211427.

Pain, D. J., A. A. Cunningham, P. F. Donald, J. W. Duckworth, D. C. Houston, T. Katzner, J. Parry-Jones, C. Poole, V. Prakash, P. Round, and R. Timmins. 2003. Causes and effects of temporospatial declines of Gyps vultures in Asia. Conservation Biology 17:661-671.

Pereira, H. M., B. Reyers, M. Watanabe, E. Bohensky, S. Foale, C. Palm, M. V. Espaldon, D. Armenteras, M. Tapia, A. Rincón, M. J. Lee, A. Patwardhan, and I. Gomes. 2005. Condition and trends of ecosystem services and biodiversity. Pages 171-203 in D. Capistrano, C. Samper, M. J. Lee, and C. Raudsepp-Hearne, editors. Ecosystems and human well-being: multi scale assessments, Volume 4. Findings of the Sub-global Assessments Working Group of the Millennium Ecosystem Assessment. Island Press, Washington, D.C., USA.

Peterson, G. D., T. D. Beard, Jr., B. E. Beisner, E. M. Bennett, S. R. Carpenter, G. D. Cumming, C. L. Dent, T. D. Havlicek. 2003. Assessing future ecosystem services: a case study of the Northern Highlands Lake District, Wisconsin. Conservation 
Ecology 7(3): 1. [online] URL: http://www.consecol. org/vol7/iss3/art1/.

Ramesh, R. 2005. Parsi tradition dying out for lack of vultures. The Guardian: 6 October 2005. [online] URL: http://www.guardian.co.uk/religion/Story/20 $\underline{00,2763,1585836,1585800 . \mathrm{html}}$.

Ricketts, T. H., G. C. Daily, P. R. Ehrlich, and C. D. Michener. 2004. Economic value of tropical forest to coffee production. Proceedings of the National Academy of Sciences of the United States of America 101:12579-12582.

Rodríguez, J. P., T. D. Beard, Jr., J. Agard, E. Bennett, S. Cork, G. Cumming, D. Deane, A. P. Dobson, D. M. Lodge, M. Mutale, G. C. Nelson, G. D. Peterson, and T. Ribeiro. 2005. Interactions among ecosystem services. Pages 431-448 in S. R. Carpenter, P. L. Pingali, E. M. Bennett, and M. B. Zurek, editors. Ecosystems and human well-being: scenarios. Volume 2. Findings of the Scenarios Working Group, Millennium Ecosystem Assessment. Island Press, Washington, D.C., USA.

Rose, S. K., and D. Chapman. 2003. Timber harvest adjacency economies, hunting, species protection, and old growth value: seeking the dynamic optimum. Ecological Economics 44:325-344.

Samraj, P., V. N. Sharda, S. Chinnamani, V. Lakshmanan, and B. Haldorai. 1988. Hydrological behavior of the Nilgiri sub-watersheds as affected by bluegum plantations. 1 . The annual waterbalance. Journal of Hydrology 103:335-345.

Schindler, D. E., S. I. Geib, and M. R. Williams. 2000: Patterns of fish growth along a residential development gradient in north temperate lakes. Ecosystems 3:229-237.

Schofield, N. J. 1992. Tree planting for dryland salinity control in Australia. Agroforestry Systems 20:1-23

Spaltro, F., and B. Provencher. 2001. An analysis of minimum frontage zoning to preserve lakefront amenities. Land Economics 77:469-481.

Stamenkovic, J., M. S. Gustin, and K. E. Dennett. 2005. Net methyl mercury production versus water quality improvement in constructed wetlands: trade-offs in pollution control. Wetlands 25:748757.
Tietenberg, T. 1996. Environmental and natural resource economics. Fourth edition. HarperCollins College Publishers, New York, New York, USA.

Tilman, D. 1999. Global environmental impacts of agricultural expansion: the need for sustainable and efficient practices. Proceedings of the National Academy of Sciences of the United States of America 96:5995-6000.

Tilman, D., K. G. Cassman, P. A. Matson, R. Naylor, and S. Polasky. 2002. Agricultural sustainability and intensive production practices. Nature 418:671-677.

van Jaarsveld, A. S., R. Biggs, R. J. Scholes, E. Bohensky, B. Reyers, T. Lynam, C. Musvoto, and C. Fabricius. 2005. Measuring conditions and trends in ecosystem services at multiple scales: the Southern African Millennium Ecosystem Assessment (SAfMA) experience. Philosophical Transactions of the Royal Society B-Biological Sciences 360:425-441.

Walker, B., S. Carpenter, J. Anderies, N. Abel, G. Cumming, M. Janssen, L. Lebel, J. Norberg, G. D. Peterson, and R. Pritchard. 2002. Resilience management in social-ecological systems: a working hypothesis for a participatory approach. Conservation Ecology 6(1):14. [online] URL: http: //www.ecologyandsociety.org/vol6/iss1/art14/.

Youth, H. 2002. What's ailing Asia's vultures. ZooGoer 31. [online] URL: http://nationalzoo.si. edu/Publications/ZooGoer/2002/2004/ailingvultures. cfm.

Zedler, J. B. 2003. Wetlands at your service: reducing impacts of agriculture at the watershed scale. Frontiers in Ecology and the Environment 1:65-72. 